\title{
PAINEL PRÉ-MOLDADO DE ARGAMASSA ARMADA COM VERMICULITA EXPANDIDA E REFORÇADO COM FIBRAS DE VIDRO
}

\section{Precast mortar panel with expanded vermiculite and fiberglass reinforcement} Daniel de Lima Araújo', Éricka da Silva Cândido²

Recebido em 04 de março de 2015; recebido para revisão em 10 de junho de 2015; aceito em 10 de setembro de 2015; disponível on-line em 09 de novembro de 2015.

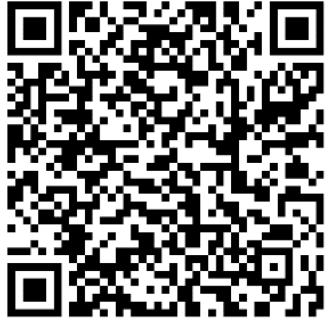

PALAVRAS CHAVE:

Painel pré-moldado

Vermiculita expandida;

Fibra de vidro.

\section{KEYWORDS:}

Precast panel;

Expanded vermiculite;

Glass fiber.

\footnotetext{
* Contato com os autores:
}

${ }^{1}$ e-mail: dlaraujo@ufg.br ( D. L. Araújo )

Engenheiro Civil, Doutor, Professor Associado, Escola de Engenharia Civil e Ambiental, Universidade Federal de Goiás (EECA/UFG).

2e-mail : erickagyn@hotmail.com ( E. S. Cândido)

Engenheira Civil, Tribunal de Contas dos Municípios do Estado de Goiás, Goiânia, GO
RESUMO: O objetivo deste trabalho é determinar o comportamento mecânico de painéis pré-moldados confeccionados com argamassa contendo apenas Vermiculita Expandida. São analisados três tipos de painéis, isto é, painéis maciços e painéis alveolares confeccionados apenas com argamassa e painéis vazados formados por um pré-painel de argamassa envolvido em uma fina camada de calda de cimento. Os painéis são reforçados com tela de aço eletrossoldada ou com tela de fibra de vidro. O comportamento mecânico dos painéis é caracterizado por meio de ensaios de flexão ou de compressão sob carregamento estático. A utilização da Vermiculita Expandida como agregado leve em argamassas para painéis diminuiu a resistência à tração na flexão dos painéis, no entanto, proporcionou um aumento de até $10 \%$ no seu isolamento térmico. A utilização da tela de fibra de vidro evitou a ruptura brusca dos painéis em escala reduzida e em painéis vazados com reforço na calda de cimento. A principal conclusão desse trabalho é mostrar a viabilidade técnica da utilização de painéis vazados leves com pré-painel em argamassa com Vermiculita expandida e reforçados com tela de fibra de vidro.

ABSTRACT: The aim of this study is to determine the mechanical behavior of precast mortar panels containing expanded vermiculite. Three types of panels are analyzed, i.e., solid panels, hollow core panels and modified hollow core panels formed of a lightweight mortar pre-panel enveloped by a thin layer of grout. The panels are reinforced with a mesh steel or fiberglass fabric. The mechanical behavior of panels is determined from bending tests or compression tests under static loading. The use of mortars with expanded vermiculite as lightweight aggregate decreases the flexural strength of panels, but increases their thermal insulation by up to $10 \%$. The use of fiberglass fabric prevents sudden failure of the modified hollow core panels. The main finding of this study is the technical feasibility of lightweight panels made of pre-cast panel mortar and expanded vermiculite reinforced with fiberglass fabric.

(C) 2015 REEC - Todos os direitos reservados.

\section{INTRODUÇÃO}

Atualmente, existe uma tendência no desenvolvimento de novas técnicas construtivas e soluções originais com a finalidade de reduzir custos e aumentar a rapidez de execução das obras. Dentre as diversas soluções que utilizam o concreto armado, a pré-fabricação mostra-se a mais adequada para essa finalidade. Além da redução do período de construção, como as peças são fabricadas em instalações industriais, há um maior controle na qualidade do concreto e do processo de execução, proporcionando um produto final de melhor qualidade. $O$ fato dos serviços de confecção da estrutura na obra resumirem-se à montagem das peças pré-fabricadas proporciona uma redução significativa nas perdas de material e no desperdício de mão de obra. 
Grande parte das moradias de interesse social tem sido executada atualmente com elementos pré-moldados na tentativa de se otimizar o processo construtivo. Nesse sentido, os painéis pré-fabricados têm contribuído enormemente, agilizando os serviços de confecção de alvenarias. Entretanto, uma das maiores dificuldades na aplicação de painéis de concreto armado pré-fabricados é o elevado peso específico do concreto que resulta em peças que necessitam de equipamentos especiais para sua montagem. Tentando reduzir esse inconveniente é que vários tipos de soluções têm sido desenvolvidas, desde a confecção de vazios no interior dos painéis até o uso de agregados leves na confecção do concreto. Essas soluções, além de reduzir o peso dos painéis, apresentam a vantagem da melhora do conforto térmico e acústico nas edificações quando comparado aos painéis maciços de concreto.

As argilas expandidas são os agregados leves comumente empregados na confecção dos concretos estruturais leves, que possuem massa específica variando entre $1400 \mathrm{~kg} / \mathrm{m}^{3}$ e $1800 \mathrm{~kg} / \mathrm{m}^{3}$ e resistência à compressão mínima de $17 \mathrm{MPa}, \mathrm{ACl}$ 318 (ACl,1994a). Além desses agregados, a Vermiculita Expandida também tem sido empregada como agregado em argamassas e concretos. Neste caso, a massa específica da argamassa fica entre $400 \mathrm{~kg} / \mathrm{m}^{3}$ e $800 \mathrm{~kg} / \mathrm{m}^{3}$, e devido a sua elevada resistência à temperatura ela é dita isolante, $\mathrm{ACl}$ 523.3R ( $\mathrm{ACl}, 1994 \mathrm{~b})$; ASTM C 332 (ASTM, 2000); NBR EB 230 (ABNT, 1969); NBR 7213 (ABNT, 1984). Entretanto, essas argamassas apresentam baixa resistência mecânica, em geral apresentando valores máximos na ordem de $3 \mathrm{MPa}$, o que limita sua aplicação em elementos estruturais. O seu uso como material de enchimento em estruturas pré-moldadas de concreto, por outro lado, é vantajoso, pois reduz o peso próprio das peças pré-moldadas, facilitando sua montagem.

Com relação à aplicação da Vermiculita Expandida como agregado leve há vários trabalhos que apresentam resultados interessantes sobre o assunto. Destacam-se, por exemplo, os trabalhos de Tenório (2005), Tenório et al. (2005a) e Tenório et al. (2005b) que tiveram como objetivo o estudo de traços de argamassa e concreto contendo Vermiculita Expandida para ser utilizado na fabricação de painéis pré-moldados tipo sanduíche. Nesses estudos, foram desenvolvidos traços de argamassas e de concretos, sendo os mesmos caracterizados no estado fresco e no estado endurecido. As argamassas obtidas apresentavam resistência à compressão variando de $2 \mathrm{MPa}$ a $7 \mathrm{MPa}$. Neste caso, a Vermiculita Expandida reduziu em mais de $50 \%$ a condutividade térmica das argamassas e diminuiu seu peso específico para um terço do peso de uma argamassa sem Vermiculita Expandida, atingindo valores da ordem de $610 \mathrm{~kg} / \mathrm{m}^{3}$.

Alguns processos construtivos utilizam um painel sanduíche com núcleo em EPS (poliestireno expandido) e placas cimentícias com espessura da ordem de $25 \mathrm{~mm}$ a $30 \mathrm{~mm}$ (Shao, Blain-Cosgrove, Robinson, 2004; Machado Junior, 2000). Neste caso, devido à pequena espessura da placa cimentícia, podem ocorrer problemas patológicos se forem empregadas armaduras metálicas como reforço (corrosão). Para evitar essas patologias diversos materiais não metálicos têm sido usados para fabricação de telas para reforço, tais como polipropileno, aramida, fibra de carbono, fibra de PVA e fibra de vidro, dentre outros. Além das telas, fibras não metálicas dispersas na matriz também têm sido empregadas como reforço com a finalidade de melhorar o desempenho à tração e à flexão da matriz cimentícia.

Há na literatura poucos trabalhos desenvolvidos com 0 intuito de avaliar o comportamento de fios ou telas de diferentes fibras, em especial a fibra de vidro, como material para reforço de painéis (El Debs e El Debs, 2007). Destaca-se o trabalho de Mu e Meyer (2000) que realizaram uma pesquisa para quantificar a eficácia de telas confeccionadas com diferentes tipos de fibras (fibra de vidro, PVA e polipropileno) e comparar o seu desempenho com o de fibras de mesmo material dispersas na matriz. Os autores observaram que as fibras dispersas na matriz, apesar das vantagens de simplicidade e economia 
na fabricação, apresentaram aderência à matriz inferior a das malhas. Além disso, para grandes deformações por flexões ou elevadas aberturas de fissuras, as fibras na forma de telas se mostraram mais eficientes com relação à limitação das deformações e da abertura de fissuras.

Diante desse cenário, o objetivo desse trabalho é o estudo de painéis pré-moldados confeccionados com argamassa leve de Vermiculita Expandida. São analisados três tipos de painéis, isto é, painéis maciços e painéis alveolares confeccionados apenas com argamassa leve e painéis vazados formados por um pré-painel de argamassa leve envolvido em uma fina camada de calda de cimento. Os painéis são reforçados com tela de aço eletrossoldada ou com tela de fibra de vidro. O comportamento mecânico desses painéis é caracterizado por meio de ensaios de flexão e de compressão sob carregamento quase estático. Também são avaliadas as propriedades térmicas do painel com argamassa leve de Vermiculita Expandida.

\section{MATERIAL E MÉTODOS}

Para o desenvolvimento dessa pesquisa foram desenvolvidos traços de argamassa leve contendo apenas Vermiculita Expandida e traços de calda cimento, isto é, uma mistura de água, cimento Portland e sílica ativa. Em alguns traços, a Vermiculita Expandida foi totalmente substituída por areia natural. O cimento Portland utilizado foi o CP-II F 32, com massa específica $\left(\gamma_{\text {cimento }}\right)$ de $3,08 \mathrm{~g} / \mathrm{cm}^{3}$. A sílica ativa empregada possuía massa específica $\left(\gamma_{\text {silica }}\right)$ de $2,2 \mathrm{~g} / \mathrm{cm}^{3}$. As propriedades físicas da areia natural e da Vermiculita Expandida utilizadas nos ensaios são mostradas na Tabela 1.

Em alguns traços, foi utilizada Bentonita dissolvida na água de mistura de modo a diminuir a absorção de água pela Vermiculita Expandida. A Bentonita utilizada foi caracterizada com relação à sua massa específica ( $\left.\gamma_{\text {bentonita }}\right)$, tendo sido obtido o valor de $2,73 \mathrm{~g} / \mathrm{cm}^{3}$. Os traços desenvolvidos tomaram como referência o trabalho de Pinto et al. (2000), cujo traço era composto de uma parte sólida constituída por cimento e Vermiculita Expandida e por uma dispersão aquosa água/bentonita. $\mathrm{O}$ traço unitário, em massa, utilizado por esses autores era: $1: 0,1: 0,7: 0,04$ (cimento : vermiculita : água : bentonita). Os traços desenvolvidos nesta pesquisa foram obtidos fixando a relação bentonita/cimento (em massa) em 0,065 e variando os teores de cimento e água, mantendo o índice de consistência em intervalos pré-estabelecidos. A relação água/cimento dos traços variou de 0,685 a 1,300. Os traços com Bentonita foram utilizados apenas no estudo da condutividade térmica, não tendo sido utilizado na confecção dos painéis.

As dosagens de argamassas com Vermiculita Expandida foram feitas em betoneira de 200 litros de capacidade. A ordem de colocação dos materiais e o tempo de mistura foram: cimento e $1 / 3$ da água de mistura (misturado por um minuto); $1 / 2$ da Vermiculita Expandida e $1 / 3$ da água de mistura (misturado por um minuto); restante da Vermiculita e da água e aditivo (quando necessário), misturado por um minuto e 30 segundos. Para a argamassa com areia, o cimento foi colocado juntamente com ela e ambos foram misturados por um minuto e 30 segundos; a água e o aditivo foram colocados posteriormente e misturados por mais um minuto e 30 segundos.

\begin{tabular}{ccc}
\hline \multicolumn{3}{c}{ TABELA 1: Propriedades físicas dos materiais. } \\
\hline Propriedade & Areia & Vermiculita Expandida \\
\hline Dimensão máxima $(\mathrm{mm})$ & 4,8 & 2,4 \\
Modulo de finura & 2,35 & 2,99 \\
Massa específica $\left(\mathrm{g} / \mathrm{cm}^{3}\right)$ & 2,62 & 2,41 \\
Massa unitária $\left(\mathrm{g} / \mathrm{cm}^{3}\right)$ & 1,44 & 0,12 \\
\hline
\end{tabular}


A dosagem da calda de cimento para os painéis vazados foi feita em misturador próprio com capacidade de 25 litros com a seguinte ordem de colocação: cimento e sílica, água e aditivo dissolvido em parte da água da mistura, totalizando cerca de seis minutos de mistura.

As argamassas foram caracterizadas quanto às seguintes propriedades mecânicas: resistência à compressão $\left(f_{c m}\right)$, conforme a norma NBR 5739 (ABNT, 1994a), resistência à tração por compressão diametral $\left(\mathrm{f}_{\mathrm{ctm}, \mathrm{sp}}\right)$, conforme a norma NBR 7222 (ABNT, 1994b), módulo de elasticidade, $\left(E_{c}\right)$, conforme a norma NBR 8522 (ABNT, 2003), massa específica aparente seca e absorção, segundo a norma NBR 9778 (ABNT, 1987). Além desses ensaios, as argamassas também foram caracterizadas quanto à condutividade térmica, segundo a NBR 12820 (ABNT, 1993). Para isso, foram utilizados dois corpos-de-prova de $20 \times 40 \mathrm{~cm}$, ensaiados oito dias depois da moldagem. $O$ equipamento usado para a realização deste ensaio está apresentado na Figura 1.

O aço dos fios da tela eletrossoldada utilizada como reforço em alguns painéis foi caracterizado quanto à sua resistência à tração, segundo a norma NBR 6207 (ABNT, 1982). As propriedades da tela de fibra de vidro foram fornecidas pelo fabricante da mesma. As principais propriedades das telas de aço e de fibra de vidro

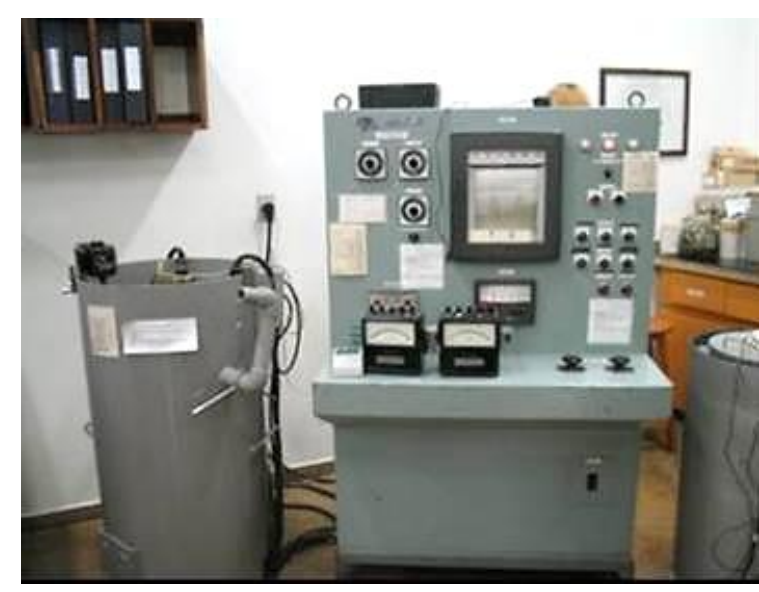

FIGURA 1: Equipamento para ensaio de condutividade térmica.

estão apresentadas na Tabela 2.

\section{ENSAIOS EM PAINÉIS}

A nomenclatura dos painéis ensaiados e suas variáveis estão apresentadas na Tabela 3. Suas formas e dimensões estão mostradas nas Figuras 2, 3 e 4 . No total, foram ensaiados três painéis em escala reduzida, três painéis em escala real (maciço e alveolar) e oito painéis vazados. Os painéis em escala real foram ensaiados à flexão enquanto os painéis vazados foram ensaiados tanto à flexão quanto à compressão. Os painéis em escala reduzida foram utilizados para o ensaio térmico e depois ensaiados à flexão. A quantidade de material, por metro cúbico, para cada tipo de painel é mostrada na Tabela 4.

\section{TABELA 2: Propriedades das telas de aço e de fibra de vidro.}

\begin{tabular}{|c|c|c|c|c|c|}
\hline \multirow{2}{*}{ Material } & \multirow{2}{*}{ Malha (mm) } & \multirow{2}{*}{$\begin{array}{l}\text { Área do } \\
\text { Fio }\left(\mathrm{mm}^{2}\right)\end{array}$} & \multicolumn{2}{|c|}{ Resistência (MPa) } & \multirow{2}{*}{$\begin{array}{l}\text { Módulo de Elast. } \\
\qquad(\mathrm{GPa})\end{array}$} \\
\hline & & & Longitudinal & Transversal & \\
\hline Aço CA-60 & $100 \times 100$ & 13,85 & \multicolumn{2}{|c|}{830,17} & 210 \\
\hline Fibra de Vidro* & $10 \times 10$ & 0,24 & 1870 & 1740 & 74 \\
\hline
\end{tabular}

* Informações fornecidas pelo fabricante 


\section{TABELA 3: Relação dos painéis analisados.}

\begin{tabular}{|c|c|c|c|c|}
\hline \multirow{2}{*}{ Nomenclatura } & \multirow{2}{*}{$\begin{array}{c}\text { Características dos } \\
\text { painéis }\end{array}$} & \multirow{2}{*}{ Localização do Reforço } & \multicolumn{2}{|c|}{ Reforço (tela) } \\
\hline & & & Quantidade & Material \\
\hline \multicolumn{5}{|c|}{ Painéis em escala reduzida } \\
\hline PNr_C_CR_VE & Maciço reduzido & Face tracionada & 01 & Fib. Vidro \\
\hline PNr_C_SR_VE & Maciço reduzido & Sem Reforço & - & - \\
\hline PNr_C_SR_A ${ }^{1}$ & Maciço reduzido & Sem Reforço & - & - \\
\hline \multicolumn{5}{|c|}{ Painéis em escala real } \\
\hline PN_M_A & Maciço & $30 \mathrm{~mm}$ de cada face & 01 & Aço \\
\hline PN_A_FV & Alveolar & $10 \mathrm{~mm}$ de cada face & 01 & Fib. Vidro \\
\hline PN_A_A & Alveolar & $10 \mathrm{~mm}$ de cada face & 01 & Aço \\
\hline \multicolumn{5}{|c|}{ Painéis vazados em escala reduzida } \\
\hline$P N \_$V_FV_PP ${ }^{2}$ & Vazado & Pré-painel de Verm. Exp & 02 & Fib. Vidro \\
\hline PN_V_FV_CC ${ }^{2}$ & Vazado & Calda de cimento & 02 & Fib. Vidro \\
\hline PN_V_A_CC ${ }^{2}$ & Vazado & Calda de cimento & 02 & Aço \\
\hline PN_V_SR ${ }^{2}$ & Vazado & Sem reforço & - & - \\
\hline
\end{tabular}

${ }^{1}$ Agregado miúdo utilizado: areia natural; todos os outros painéis são confeccionados apenas com Vermiculita Expandida; ${ }^{2}$ Para os painéis vazados, foram moldados 2 painéis de cada tipo para ensaios de flexão e de compressão.

TABELA 4: Traços de argamassa e calda de cimento (quantidade por metro cúbico).

\begin{tabular}{|c|c|c|c|c|c|c|c|c|}
\hline Tipo de painel & $\begin{array}{l}\text { Cimento } \\
(\mathrm{kg})\end{array}$ & $\begin{array}{l}\text { Sílica } \\
\text { ativa } \\
(\mathrm{kg})\end{array}$ & $\begin{array}{c}\text { Areia } \\
\text { Natural } \\
(\mathrm{kg})\end{array}$ & $\begin{array}{c}\text { Vermic. } \\
\text { Exp. } \\
\text { (kg) }\end{array}$ & $\begin{array}{l}\text { Água } \\
\text { (L) }\end{array}$ & $\begin{array}{l}\text { Bentonita } \\
\text { (kg) }\end{array}$ & $\begin{array}{l}\text { Aditivo } \\
(\% \mathrm{C})\end{array}$ & $\begin{array}{c}\text { Relação } \\
\text { a/c }\end{array}$ \\
\hline Painéis reduzidos & 467,3 & - & - & 163,5 & 610,0 & 31,2 & - & 1,305 \\
\hline $\begin{array}{l}\text { Painel reduzido com } \\
\text { areia }\end{array}$ & 402,0 & - & 1333,3 & - & 230,1 & - & 0,36 & 0,572 \\
\hline $\begin{array}{c}\text { Painéis alveolares e } \\
\text { maciços }\end{array}$ & 403,7 & - & - & 157,8 & 533,6 & - & & 1,322 \\
\hline $\begin{array}{l}\text { Pré-painéis para os } \\
\text { painéis vazados }\end{array}$ & 444,4 & - & - & 154,4 & 522,1 & - & - & 1,175 \\
\hline $\begin{array}{l}\text { Calda de cimento } \\
\text { para painéis vazados }{ }^{1}\end{array}$ & 965,0 & 60,0 & - & - & 630,0 & - & 0,8 & 0,653 \\
\hline
\end{tabular}

${ }^{1}$ Para o painel PN_V_A_CC ensaiado à flexão, a porcentagem de aditivo foi de $0,4 \%$.

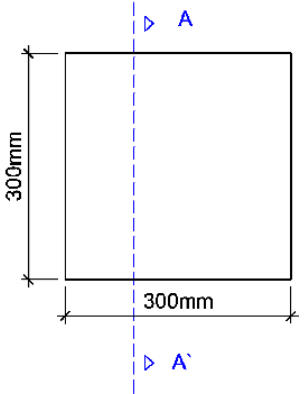

[a]

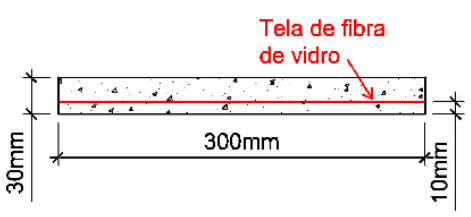

[b]

Obs.: No painel com argamassa convencional (PNr_C_SR_A), o comprimento e a largura eram de $280 \mathrm{~mm}$ e a espessura era de $28 \mathrm{~mm}$ (valores nominais).

FIGURA 2: Dimensões dos painéis maciços reduzidos: [a] planta; [b] corte $A A^{\prime}$. 


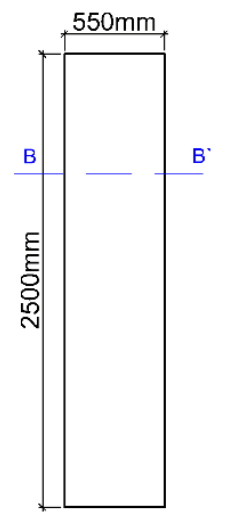

[a]

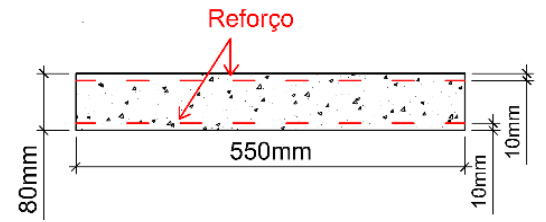

[b]

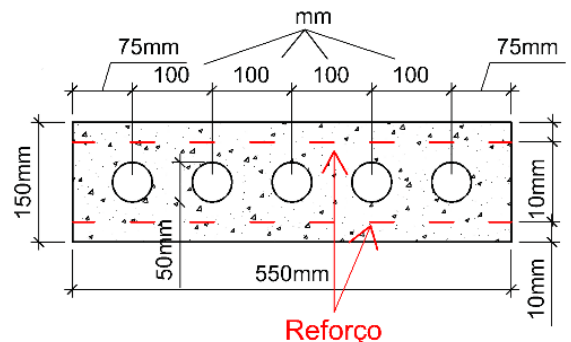

[c]

FIGURA 3: Painéis maciços e alveolares em escala real: [a] planta; [b]corte BB' no painel maciço; [c] corte BB' no painel alveolar.

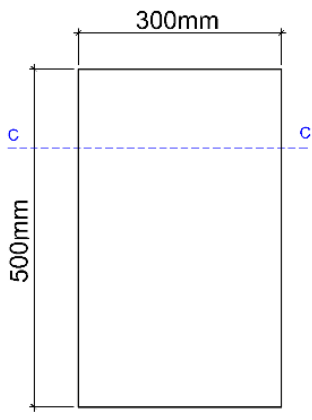

[a]

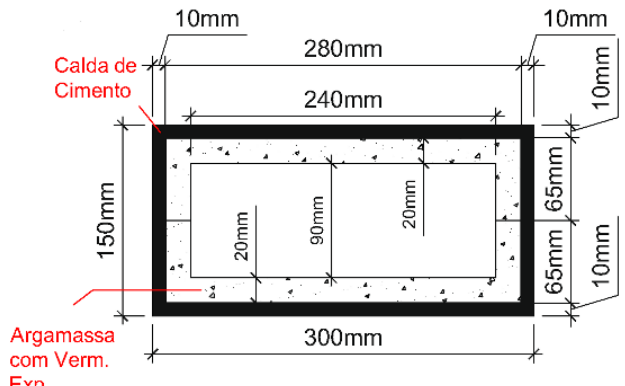

[b]

Obs.: Nos painéis vazados com reforço em telas de aço, a largura dos pré-painéis era de $260 \mathrm{~mm}$ e a espessura da calda de cimento era de $20 \mathrm{~mm}$.

FIGURA 4: Painel vazado: [a] planta; [b] corte C C'.

Os painéis alveolares em escala real possuíam $2500 \mathrm{~mm}$ de comprimento, $55 \mathrm{~mm}$ de largura e $150 \mathrm{~mm}$ de espessura. Eles foram concretados em fôrma metálica e os alvéolos foram garantidos por cinco tubos metálicos de $50 \mathrm{~mm}$ de diâmetro e espaçados de $100 \mathrm{~mm}$. Um dos painéis foi reforçado com tela de aço eletrossoldada enquanto o outro painel foi reforçado com tela de fibra de vidro (Figura 5). O painel maciço possuía a mesma dimensão do painel alveolar, porém com $100 \mathrm{~mm}$ de espessura, e foi reforçado com tela de aço eletrossoldada. Esses painéis foram mantidos em cura úmida até dois dias antes da data de ensaio, realizado, em média, 28 dias após a concretagem.

Os painéis vazados são compostos por dois pré-painéis de argamassa com Vermiculita Expandida recobertos por uma fina camada de calda de cimento. Esses painéis foram confeccionados em duas etapas: concretagem dos pré-painéis e preenchimento com a calda de cimento. Os pré-painéis foram concretados em fôrmas de madeira retangulares nas quais foi colocado isopor de modo a dar o formato em " $U$ " para o pré-painel. A desforma era feita no dia seguinte à concretagem e os pré-painéis eram unidos, em pares, com argamassa a fim de formarem o pré-painel vazado. Este permanecia em cura úmida, em média, por três dias. Após esse período, o pré-painel era retirado da cura e envolvido com a tela de fibra de vidro ou com a tela de aço, dependendo do modelo analisado. Em seguida, o mesmo era recoberto com a calda de cimento. Para tanto, ele era posicionado dentro de uma fôrma de madeira vertical e então era realizado o preenchimento com a calda de cimento. 
A sequência de confecção dos painéis vazados está representada na Figura 6 . 0 painel concluído permanecia em cura úmida até a data do ensaio, que foi realizada, em média, 28 dias após a concretagem da calda de cimento.

Os painéis maciços reduzidos foram submetidos a ensaios de flexão com carregamento quase estático e ensaios térmicos. O ensaio de flexão foi realizado com aplicação de uma força concentrada no meio do vão (Figura 7). O objetivo da análise do desempenho térmico foi avaliar a real contribuição e eficácia das argamassas contendo Vermiculita Expandida com relação ao aumento do conforto térmico em edificações. Para o ensaio térmico foi utilizada uma caixa em madeira com oito lâmpadas de $60 \mathrm{~W}$ distribuídas uniformemente em seu interior, nas dimensões de $200 \times 600 \times 1200 \mathrm{~mm}$, revestida internamente em papel alumínio (Figura 8). Foram realizadas sete medições de temperatura, em intervalos de 30 minutos, até o tempo total de 180 minutos de ensaio. Nas faces não expostas diretamente ao calor, a medição foi realizada por meio de termômetro a laser e no interior da caixa foi realizada por meio de termopares.

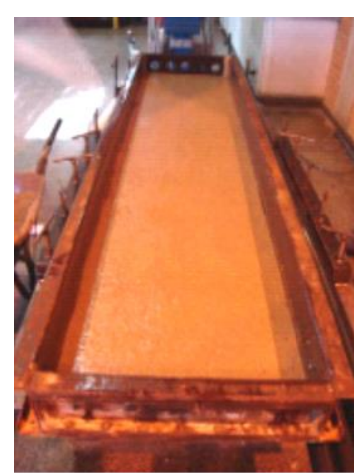

[a]

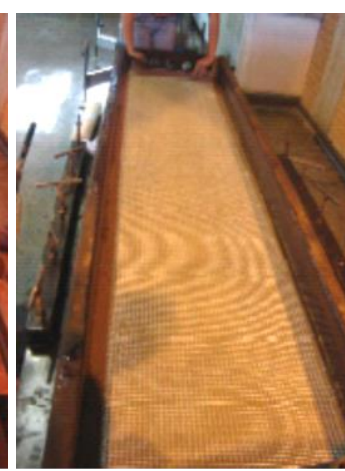

[b]

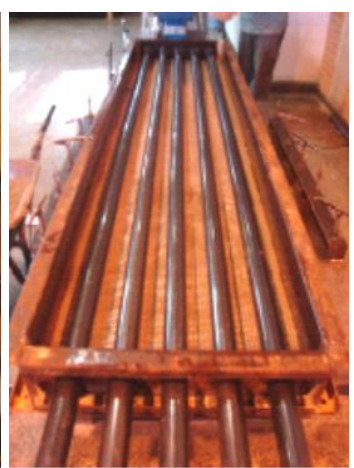

[c]

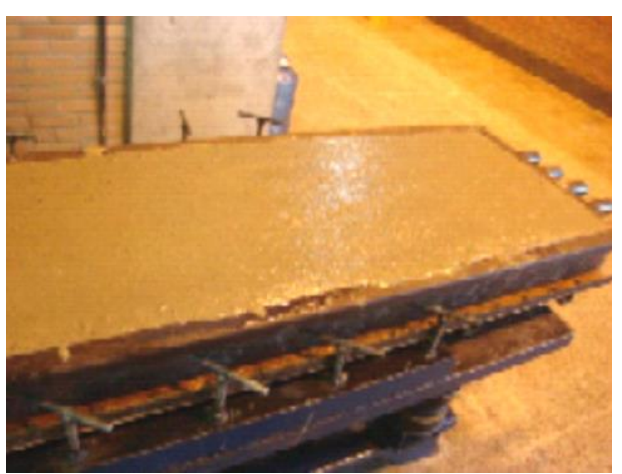

[d]

FIGURA 5: Concretagem do painel alveolar com tela de fibra de vidro: [a]1 $1^{\text {a }}$ concretagem; [b] colocação da $1^{\mathrm{a}}$ tela; [c] colocação dos tubos; [d] painel concluído após colocação da $2^{\mathrm{a}}$ tela.

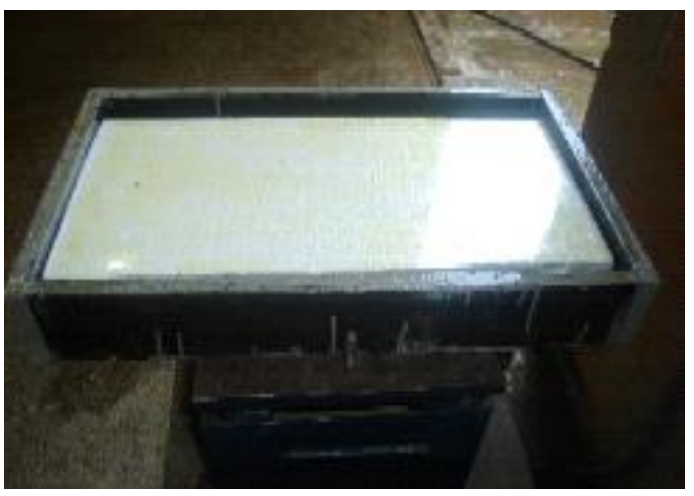

[a]

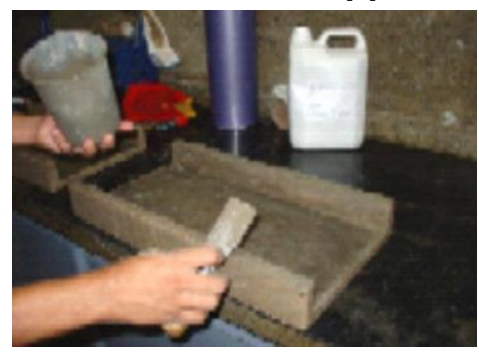

[c]

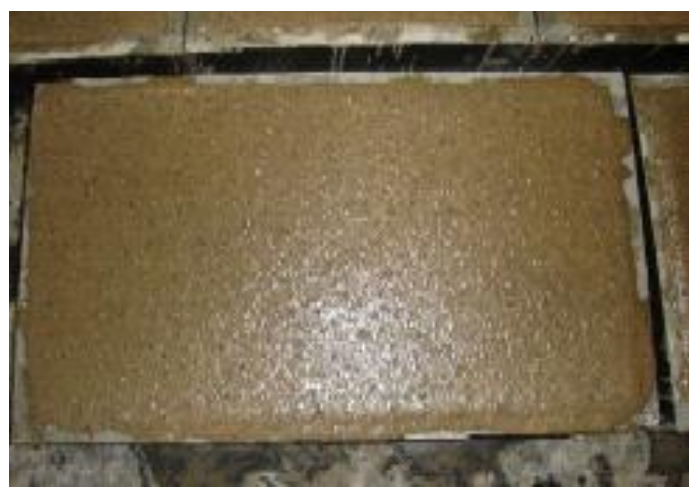

[b]

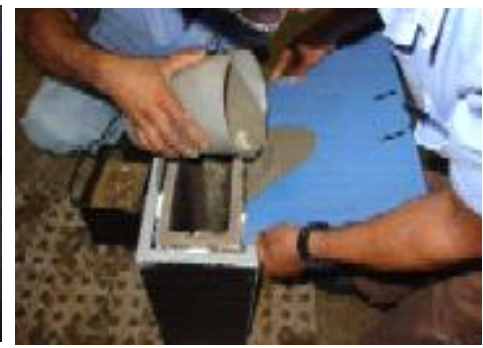

[e]

FIGURA 6: Sequência para confecção dos painéis vazados: (a) Fôrma dos pré-painéis; (b) Concretagem dos pré-painéis; (c) Preparação dos pré-painéis; (d) Par de pré-painéis; (e) Colocação da calda de cimento. 

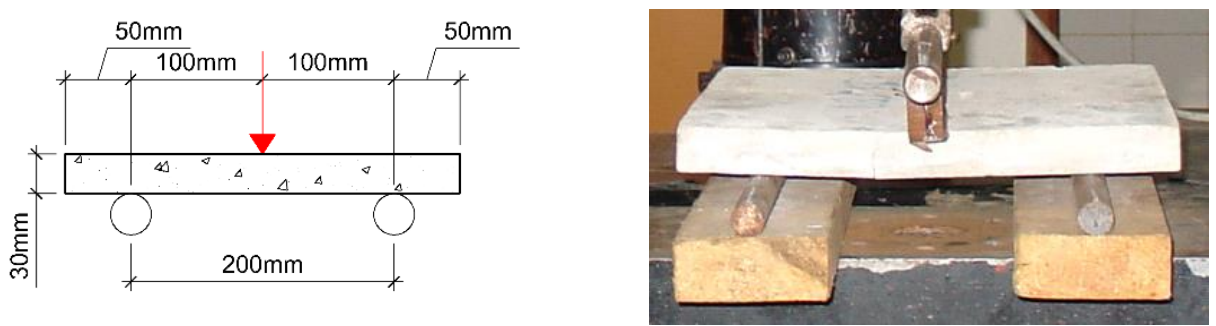

FIGURA 7: Esquema de carregamento em três pontos nos painéis maciços reduzidos.
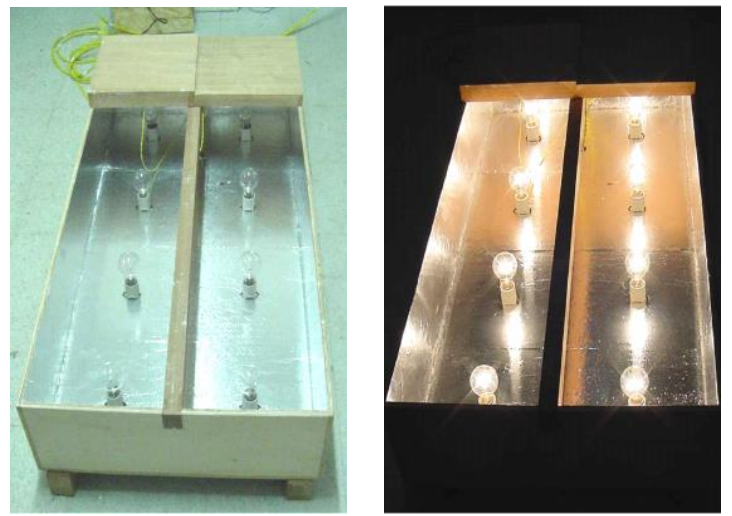

FIGURA 8: Caixa quente utilizada no ensaio térmico.

Os painéis maciços e alveolares, em escala real, foram submetidos a ensaios de flexão. No esquema de ensaio adotado, o carregamento foi aplicado de baixo para cima nos terços médios do painel, ao longo de sua largura, conforme mostrado na Figura 9.

Os painéis vazados foram ensaiados à flexão e à compressão. $O$ ensaio de flexão foi realizado aplicando uma força concentrada no meio do vão sendo o deslocamento vertical medido no meio do vão por meio de um transdutor linear (Figura 10). O ensaio à compressão seguiu o esquema apresentado na Figura 10b, no qual foi empregado uma chapa metálica na face superior do painel para uniformização do carregamento. Ambos os ensaios foram realizados com controle de deslocamento, tendo sido adotada uma velocidade de carregamento de $0,1 \mathrm{~mm} / \mathrm{s}$ no ensaio de flexão e $0,5 \mathrm{~mm} / \mathrm{s}$ no ensaio de compressão.
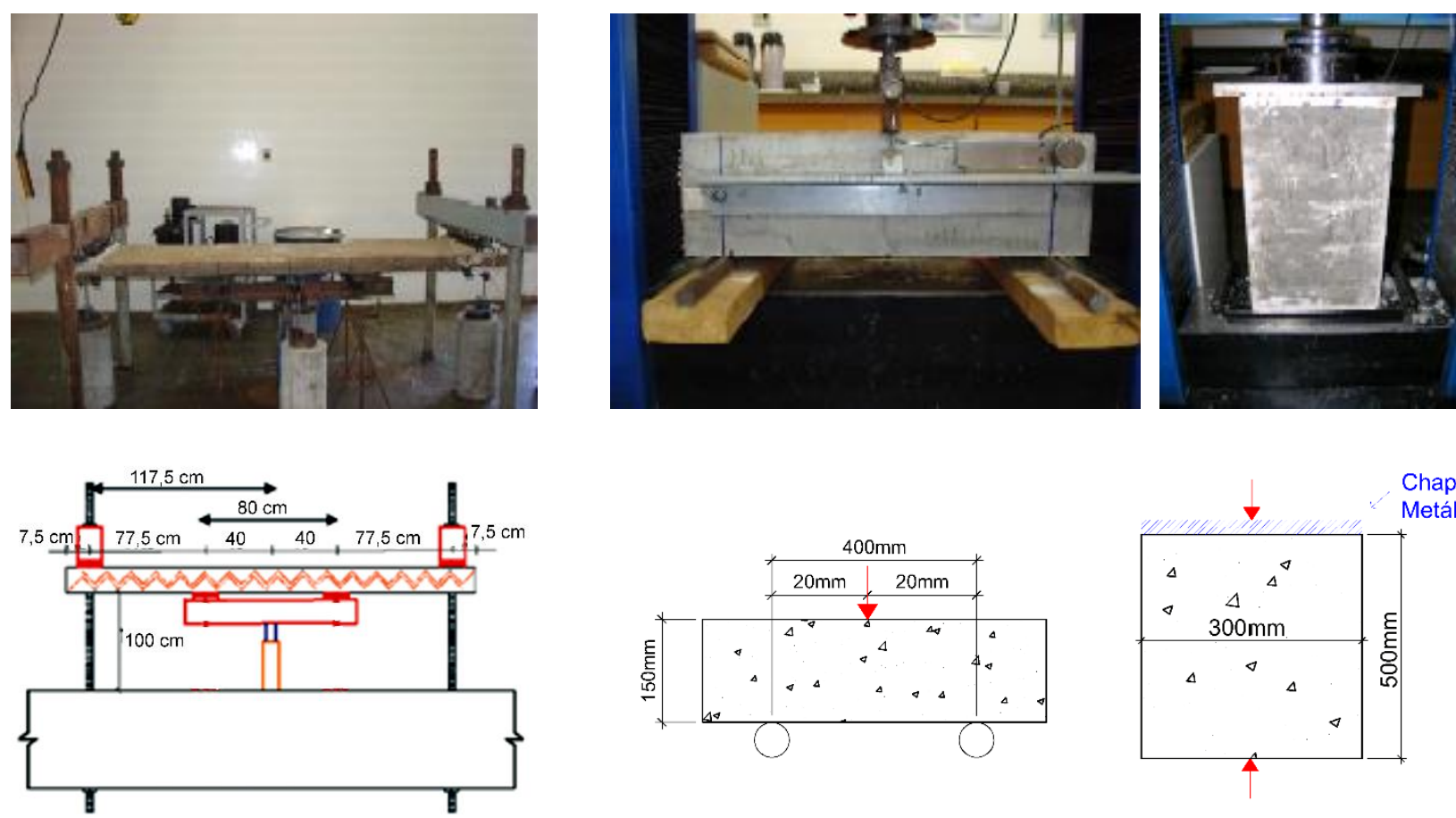

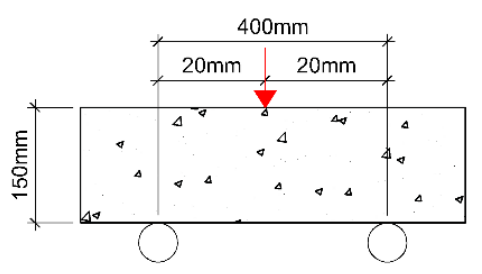

[a]

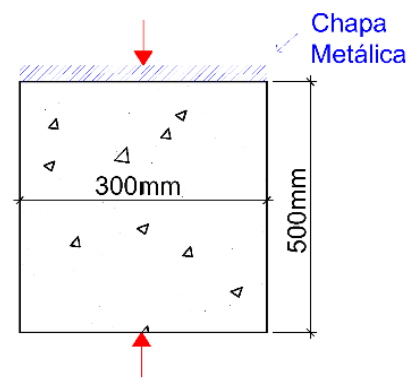

[b]

FIGURA 9: Esquema de ensaio à flexão dos painéis em escala real.

FIGURA 10: Esquema de ensaio dos painéis vazados: [a] flexão; [b] compressão. 


\section{RESULTADOS E DISCUSSÕES}

\subsection{ENSAIOS DE PAINÉIS EM ESCALA REDUZIDA}

Inicialmente, esses painéis foram submetidos a ensaio para avaliação de seu desempenho térmico. Os painéis de argamassa contendo Vermiculita Expandida apresentaram melhor capacidade de isolamento térmico que o painel de referência confeccionado sem Vermiculita, pois ocorreu menor variação de temperatura na face não exposta diretamente à fonte de calor (Figura 11). A presença da tela de fibra de vidro aumentou a condutividade do painel, porém a temperatura nestes painéis ainda foi inferior à do painel de referência. Após 180 minutos, a temperatura nos painéis com Vermiculita Expandida foi, em média, cerca de 10\% inferior à do painel de referência.

A análise do resultado de condutividade térmica obtida do ensaio em corpos-de-prova cilíndricos de $20 \mathrm{~cm} \times 40 \mathrm{~cm}$ indica uma redução mais acentuada da condutividade devido à presença da Vermiculita Expandida que a observada no ensaio dos painéis. A condutividade variou de $0,91 \mathrm{~W} / \mathrm{m}^{\circ} \mathrm{C}$ a $1,09 \mathrm{~W} / \mathrm{m}^{\circ} \mathrm{C}$ nos traços com Vermiculita Expandida, enquanto no traço de referência, sem Vermiculita, a condutividade térmica foi de $2,52 \mathrm{~W} / \mathrm{m}^{\circ} \mathrm{C}$ (Figura 12 ). Isto é, a adição de Vermiculita reduziu em quase 64\% a condutividade térmica da argamassa. O menor valor de condutividade obtido, correspondente a uma argamassa com massa específica seca de $710 \mathrm{~kg} / \mathrm{m}^{3}$, ainda é mais de três vezes superior ao valor de $0,26 \mathrm{~W} / \mathrm{m}^{\circ} \mathrm{C}$ recomendado pelo $\mathrm{ACl} 523.3 \mathrm{R}$ $(\mathrm{ACl}, 1994 \mathrm{~b})$ para concretos isolantes e massa específica em torno de $800 \mathrm{~kg} / \mathrm{m}^{3}$ e mais de duas vezes maior que o valor fornecido pelo poliestireno expandido, que é de $0,4 \mathrm{~W} / \mathrm{m}^{\circ} \mathrm{C}$. Isto mostra que a argamassa com Vermiculita Expandida não pode ser considerada isolante, porém pode ser utilizada com sucesso para reduzir a transferência de calor para o interior de edificações em regiões de temperaturas moderadas.

A partir de corpos-de-prova cilíndricos (50 mm x $100 \mathrm{~mm}$ ) foram determinadas as propriedades mecânicas das argamassas utilizadas na confecção dos painéis, sendo os valores obtidos apresentados na Tabela 5. A argamassa confeccionada sem Vermiculita (PNr_C_SR_A) apresentou maior resistência, módulo de elasticidade e massa específica seca, além de menor valor de absorção. Comparando com a argamassa com Vermiculita Expandida, é bastante acentuada a redução da resistência e do módulo de elasticidade. Isso se deve à baixa resistência mecânica da Vermiculita Expandida utilizada como agregado e do maior fator

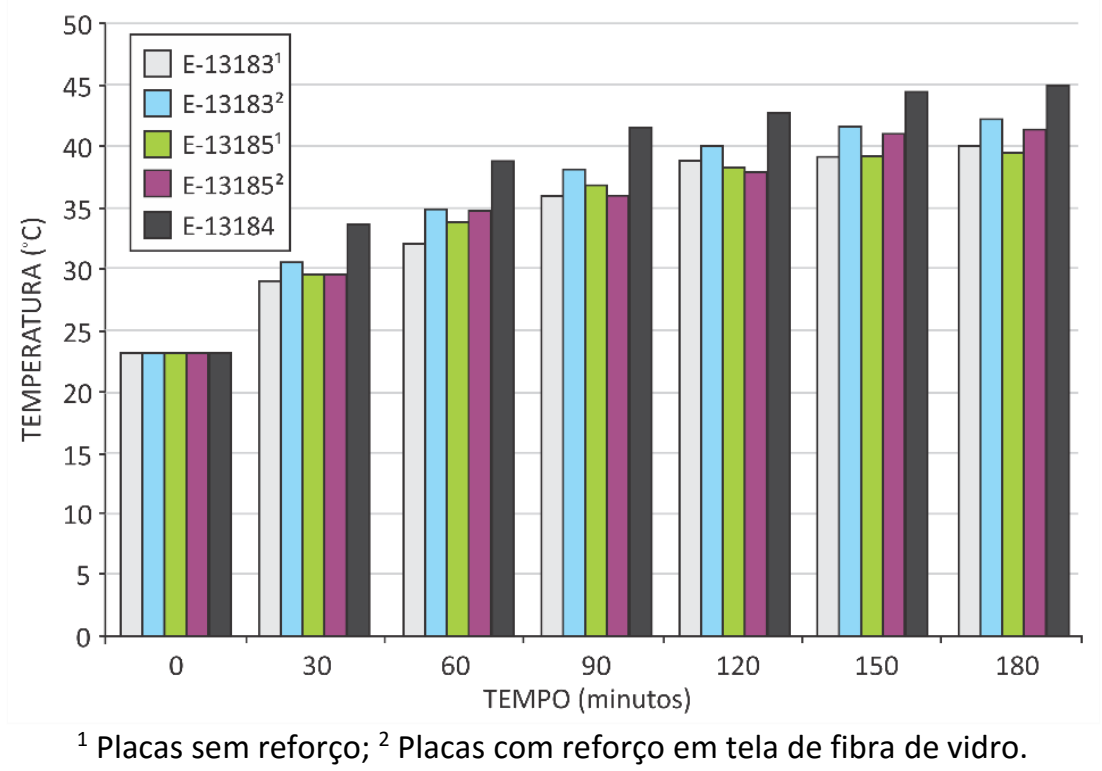

FIGURA 11: Temperatura versus Tempo no ensaio térmico dos painéis reduzidos. 
água/cimento necessário para a mistura dessa argamassa.

Do ensaio de flexão dos painéis foi determinada uma força última de $0,85 \mathrm{kN}, 1,91 \mathrm{kN}$ e 3,26 kN para os painéis com Vermiculita sem reforço, com Vermiculita e reforço em tela de fibra de vidro e sem Vermiculita, respectivamente. Desses valores observa-se um aumento de $124 \%$ na força última do painel com Vermiculita e reforço devido à presença da tela de fibra de vidro, o que demonstra uma boa aderência entre a fibra de vidro e a argamassa com Vermiculita Expandida. Apesar disso, a força última desse painel foi menor que a força última do painel com argamassa de referência confeccionada apenas com areia e sem reforço, o que demonstra a principal deficiência da adição de Vermiculita Expandida à argamassa que é a redução de sua resistência mecânica.

\subsection{ENSAIOS EM PAINÉIS MACIÇOS E ALVEOLARES}

Verificada a possibilidade de se reforçar painéis de argamassa com Vermiculita Expandida com tela de fibra de vidro, passou-se à confecção e ensaio de três painéis em escala real, dois alveolares e um maciço. Cada painel teve as propriedades mecânicas da argamassa caracterizada a partir de ensaios de corpos-deprova cilíndricos de $50 \mathrm{~mm}$ x $100 \mathrm{~mm}$. Os resultados obtidos são mostrados na Tabela 6 .

Do ensaio de flexão desses painéis, foram determinadas a resistência do painel, as deformações do aço (PN_A_A, PN_M_A), tanto comprimido quanto tracionado, as deformações do concreto comprimido e o deslocamento vertical de cada painel. Esses resultados estão apresentados nos gráficos das Figuras 13 e 14.

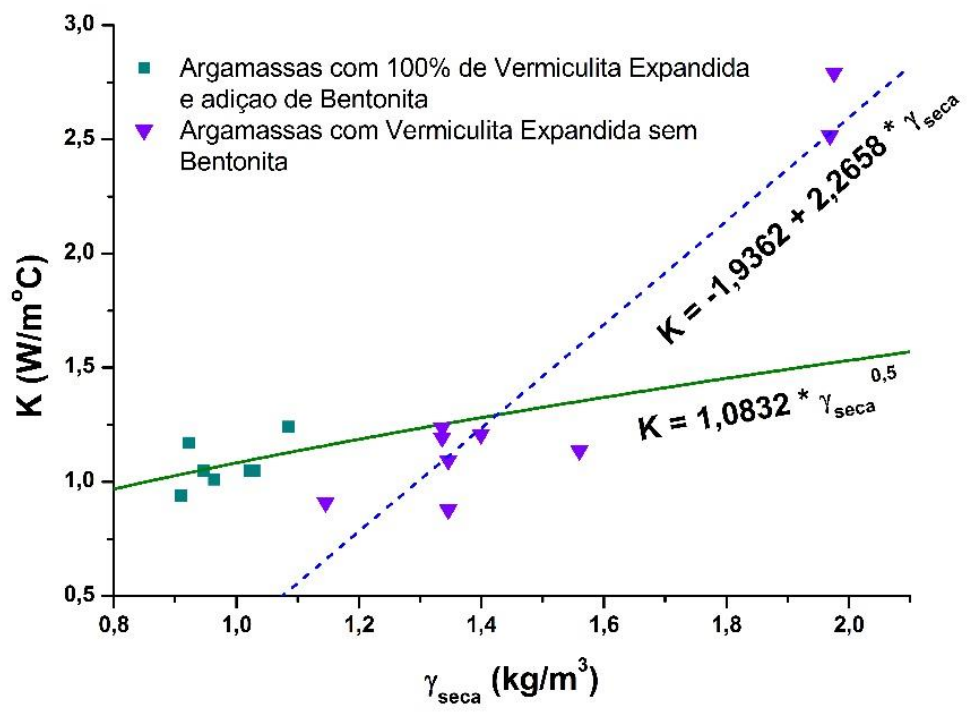

FIGURA 12: Condutividade térmica versus massa específica seca para as argamassas com Vermiculita Expandida.

Tabela 5: Propriedades mecânicas das argamassas no estado endurecido usadas nos painéis em escala reduzida.

\begin{tabular}{cccccc} 
Classificação & $\begin{array}{c}\mathrm{f}_{\mathrm{cm}} \\
(\mathrm{MPa})\end{array}$ & $\begin{array}{c}\mathrm{f}_{\mathrm{ctm}, \mathrm{sp}} \\
(\mathrm{MPa})\end{array}$ & $\begin{array}{c}\mathrm{E}_{\mathrm{c}} \\
(\mathrm{GPa})\end{array}$ & $\begin{array}{c}\text { Massa Esp. } \\
\text { Seca } \\
\left(\mathrm{kg} / \mathrm{dm}^{3}\right)\end{array}$ & $\begin{array}{c}\text { Absorção } \\
(\%)\end{array}$ \\
\hline $\begin{array}{c}\text { PNr_C_SR_VE } \\
\text { PNr_C_CR_VE }\end{array}$ & $2,67 \pm 0,15$ & $0,43 \pm 0,04$ & $2,07 \pm 0,06$ & 0,71 & 76,39 \\
PNr_C_SR_A & $20,30 \pm 1,61$ & $1,24 \pm 0,52$ & $17,70 \pm 1,51$ & 1,90 & 10,06 \\
\hline
\end{tabular}


A avaliação da resistência teórica desses painéis foi realizada admitindo dois possíveis modos de ruína, isto é, ruína por flexão ou por cisalhamento. A resistência à flexão $\left(P_{f, t}\right)$ foi determinada a partir do equilíbrio de forças na seção do meio do vão admitindo que o reforço (aço ou fibra de vidro) atingia sua máxima capacidade resistente. A resistência ao cisalhamento do painel $\left(P_{s, t}\right)$ foi determinada a partir das recomendações do Eurocode 2 (CEN, 2004), Equação 1, e do ACl 318 (ACl, 2005), Equação 2, empregadas para o cálculo da parcela resistente ao cisalhamento do concreto simples $\left(V_{c}\right)$.

$$
\mathrm{V}_{\mathrm{c}}=0,6 \mathrm{f}_{\mathrm{ct}, \mathrm{sp}} \mathrm{b}_{\mathrm{w}} \mathrm{d}
$$

$V_{c}=0,166 \times 0,75 \sqrt{f_{c}} b_{w} d$ (concreto leve) Eq. [2]

\section{Em que:}

$\mathbf{f}_{\mathrm{ct}, \mathrm{sp}}=$ resistência à tração do concreto por compressão diametral;

$\mathbf{f}_{\mathbf{c}}=$ resistência à compressão do concreto;

$\mathbf{b}_{\mathbf{w}}=$ largura da seção transversal;

d = altura de cálculo da seção transversal.

TABELA 6: Propriedades mecânicas das argamassas no estado endurecido usadas nos painéis alveolares e maciços.

\begin{tabular}{cccccc} 
Painel & $\begin{array}{c}\mathrm{f}_{\mathrm{cm}} \\
(\mathrm{MPa})\end{array}$ & $\mathrm{f}_{\mathrm{ctm}, \mathrm{sp}}(\mathrm{MPa})$ & $\begin{array}{c}\mathrm{E}_{\mathrm{c}} \\
(\mathrm{GPa})\end{array}$ & $\begin{array}{c}\text { Massa Esp. } \\
\text { Seca } \\
\left(\mathrm{kg} / \mathrm{dm}^{3}\right)\end{array}$ & $\begin{array}{c}\text { Absorção } \\
(\%)\end{array}$ \\
\hline PN_A_A & 2,2 & 0,46 & $-*$ & 0,63 & 96,21 \\
PN_A_FV & 2,8 & 0,42 & $-*$ & 0,69 & 78,39 \\
PN_M_A & 2,7 & 0,43 & 1,8 & 0,68 & 63,71 \\
\hline
\end{tabular}

* Ensaio não realizado por problemas internos no laboratório

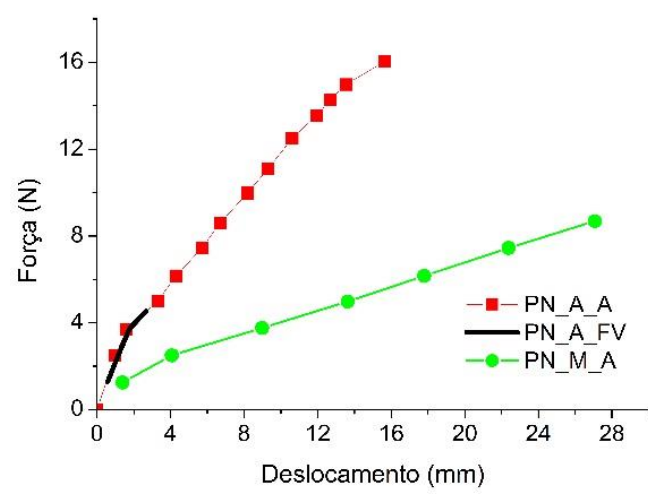

[a]

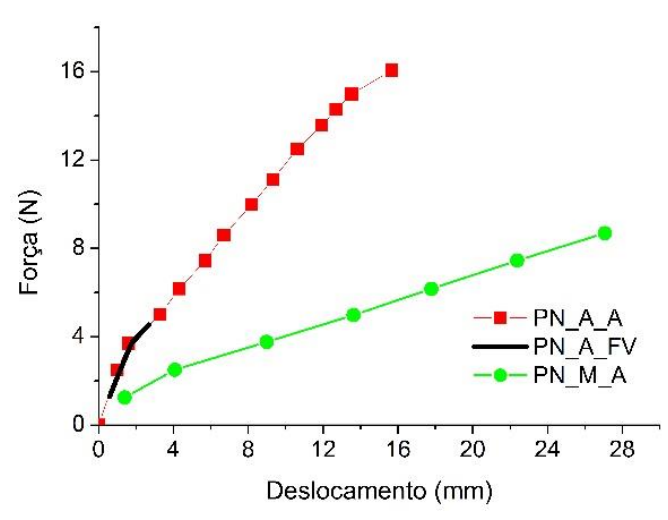

[b]

FIGURA 13: Resultados dos ensaios de flexão dos painéis maciços e alveolares: [a] Deslocamento no meio do vão; [b] Deformação na fibra superior do concreto no meio do vão. 


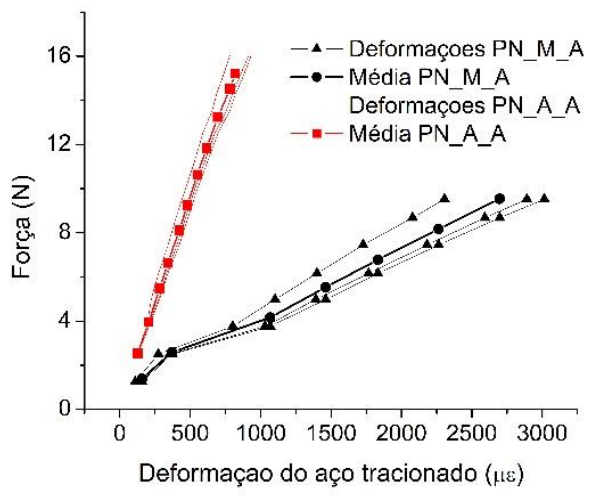

[a]

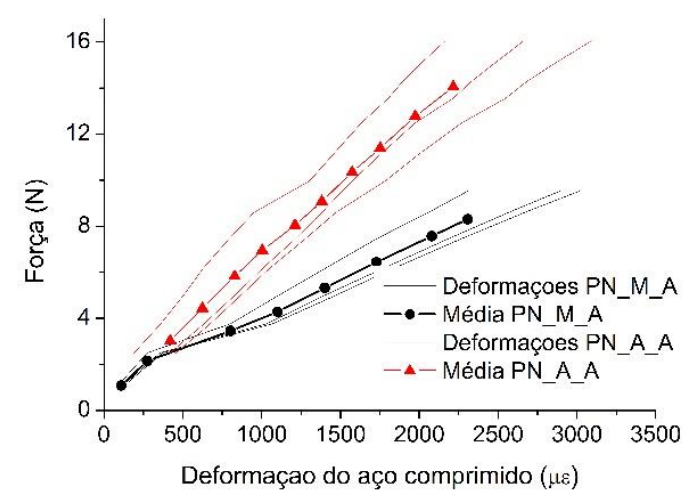

[b]

FIGURA 14: Resultados dos ensaios de flexão dos painéis maciços e alveolares: [a] Deformação na armadura longitudinal tracionada no meio do vão; [b] Deformação na armadura longitudinal comprimida no meio do vão.

$\mathrm{Na}$ Tabela 7 são mostradas as resistências obtidas experimentalmente e os valores calculados teoricamente. Nesta tabela também são indicados o modo de ruína do painel (Figura 15) e sua eficiência, definida pela relação entre sua resistência e o seu peso.

Segundo a Figura 13 e a Tabela 7, o painel maciço (PN_M_A) mostrou-se mais flexível que os painéis alveolares (PN_A_A e PN_A_FV) e apresentou uma força última menor que a do painel alveolar reforçado com tela de aço (PN_A_A). A maior inércia do painel alveolar garantiu uma deformação menor que a do painel maciço, o que resultou em uma maior resistência.

Ainda de acordo com a Tabela 7, o painel com tela de fibra de vidro (PN_A_FV) deveria ter rompido por cisalhamento, porém o mesmo rompeu por flexão. Isso indica que a expressão do $\mathrm{ACl} 318(\mathrm{ACl}, 2005)$ é conservadora para esse tipo de argamassa. Além disso, a resistência teórica à flexão foi cerca de $67 \%$ maior que a resistência obtida experimentalmente, o que indica que a consideração de aderência perfeita entre a tela e argamassa pode não ser verdadeira. A diminuição da resistência à flexão pode ter ocorrido pelo escorregamento da tela com a argamassa, o que implica em maiores valores de deformação na tela tracionada antes da ruína.

Já o painel maciço com tela de aço (PN_M_A) rompeu por cisalhamento, mas deveria ter rompido por flexão. Isso pode estar relacionado à grande curvatura observada nesse painel, que mobilizou esforços de membrana na armadura tracionada. Isso pode ser notado quando se observa que a deformação da armadura nesse painel foi bem superior à observada no painel alveolar. Sendo assim, a avaliação da resistência à flexão considerando o painel no seu eixo indeformado pode subestimar sua resistência.

Observa-se, ainda, que o painel alveolar com tela de aço (PN_A_A) foi o mais eficiente dentre os analisados, sendo sua eficiência $21,6 \%$ superior à do painel maciço com tela de aço (PN_M_A). O painel alveolar com fibra de vidro (PN_A_FV) apresentou o menor valor para essa relação, demonstrando que a tela de fibra de vidro neste caso foi bem menos eficiente que a tela de aço.

TABELA 7: Resistências à flexão e ao cisalhamento dos painéis alveolares e maciços.

\begin{tabular}{|c|c|c|c|c|c|c|}
\hline \multirow{2}{*}{ Painel } & \multirow{2}{*}{$\begin{array}{l}P_{f, t} \\
(k N)\end{array}$} & \multicolumn{2}{|c|}{$\begin{array}{c}P_{s, t} \\
(k N)\end{array}$} & \multirow{2}{*}{$\begin{array}{l}P_{\text {exp. }} \\
(k N)\end{array}$} & \multirow{2}{*}{ Tipo de ruptura } & \multirow{2}{*}{$\frac{\mathrm{P}_{\text {exp }}}{\mathrm{P}_{\text {eso,painel }}}$} \\
\hline & & Eurocode 2 & $\mathrm{ACl} 318$ & & & \\
\hline PN_A_A & 21,44 & 12,42 & 3,80 & 16,05 & Cisalhamento & 9,73 \\
\hline PN_A_FV & 7,56 & 11,205 & 3,61 & 4,54 & Flexão & 3,13 \\
\hline PN_M_A & 5,75 & 11,22 & 3,57 & 9,52 & Cisalhamento & 8,00 \\
\hline
\end{tabular}




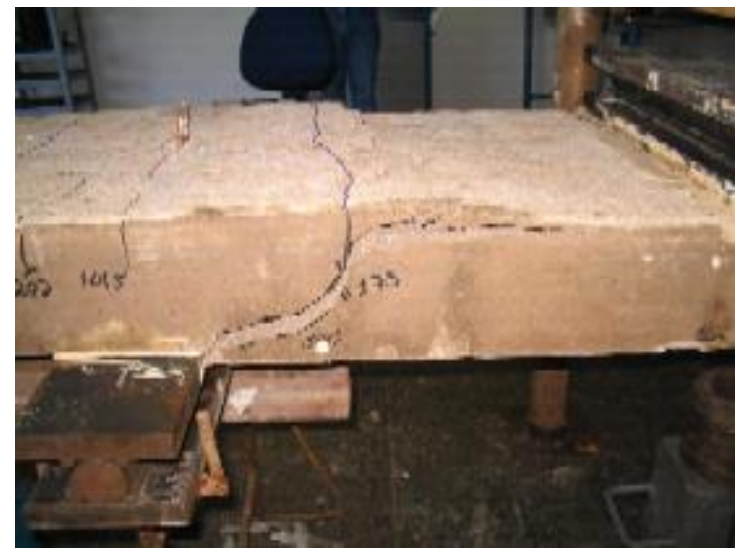

[a]

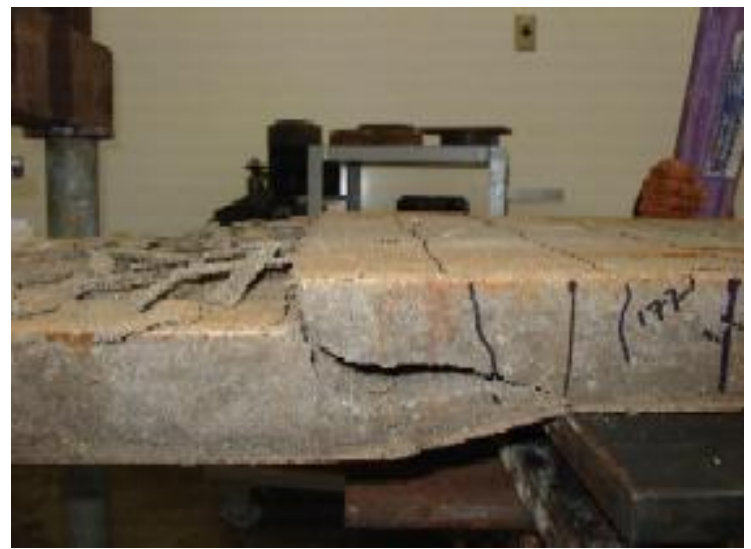

[b]

Obs.: A ruptura do PN_A_FV foi por flexão e caracterizou-se por uma ruptura brusca.

FIGURA 15: Modo de ruína do painel alveolar com tela de aço [a] e do painel maciço [b].

\subsection{ENSAIOS EM PAINÉIS VAZADOS}

O estudo desses painéis visou obter um painel leve e ao mesmo tempo mais resistente que $o$ painel confeccionado apenas com argamassa leve de Vermiculita Expandida mostrado no item 4.2. Esses painéis foram ensaiados à flexão (carregamento sob três pontos de carga) e à compressão. As propriedades mecânicas da argamassa e da calda de cimento usadas na confecção dos painéis são apresentadas na Tabela 8.

Do ensaio de compressão foi obtida a resistência última de cada painel $\left(P_{\text {exp,c) }}\right.$. Com as dimensões reais dos painéis $e$ as propriedades das argamassas e caldas de cimento, foram calculadas as resistências teóricas $\left(P_{t, c}\right)$ mostradas na Tabela 9. Por essa tabela, observa-se que os valores teóricos obtidos foram muito superiores aos experimentais. A baixa resistência experimental pode ser devida ao esmagamento no topo e na base dos painéis, que pode ter influenciada a resistência final dos mesmos.

Na Figura 16 é apresentada a curva força-deslocamento no meio do vão obtida do ensaio de flexão. Dessa figura observa-se que a presença das telas de aço e de fibra de vidro evitou a queda brusca docarregamento após a fissuração inicial dos painéis, diferentemente do que ocorreu no painel sem reforço. Além disso, o posicionamento da tela de fibra de vidro na calda de cimento mostrou-se eficiente, uma vez que após o surgimento da primeira fissura o painel ainda suportou acréscimos de carregamento.

Foi também determinada a resistência teórica desses painéis, admitindo dois modos de ruptura, isto é, ruína por flexão ou por cisalhamento. A resistência à flexão $\left(P_{f, t}\right)$ foi determinada a partir do equilíbrio de forças na seção do meio do vão admitindo que o reforço (aço ou fibra de vidro) atingia sua máxima capacidade resistente. A resistência ao cisalhamento do painel $\left(P_{s, t}\right)$ foi determinada a partir das recomendações do Eurocode 2 (CEN, 2004), Equação 1, e do $\mathrm{ACl} 318$ (ACl, 2005), Equação 2 e Equação 3, empregadas para o cálculo da parcela resistente ao cisalhamento do concreto simples $\left(\mathrm{V}_{\mathrm{c}}\right)$. Neste caso, a Equação 3 foi empregada pelo fato do $\mathrm{ACl} 318$ (ACl, 2005) especificar relações diferentes para concretos leves e de peso convencional, que é o caso da calda de cimento desses painéis. 
TABELA 8: Propriedades mecânicas da argamassa e da calda de cimento nos painéis vazados.

\begin{tabular}{|c|c|c|c|c|c|c|}
\hline Painel & Material & $\begin{array}{c}f_{c m} \\
(\mathrm{MPa})\end{array}$ & $\mathrm{f}_{\mathrm{ctm}, \mathrm{sp}}(\mathrm{MPa})$ & $\begin{array}{c}E_{c} \\
(\mathrm{GPa})\end{array}$ & $\begin{array}{c}\text { Massa Esp. Seca } \\
\left(\mathrm{kg} / \mathrm{dm}^{3}\right)\end{array}$ & $\begin{array}{c}\text { Absorção } \\
(\%)\end{array}$ \\
\hline \multirow{2}{*}{$P N \_V \_F V \_P P C$} & Arg. Vermiculita & 2,4 & 0,49 & 1,9 & 0,67 & 68,74 \\
\hline & Calda de Cimento & 15,3 & 2,48 & 8,7 & 1,28 & 37,23 \\
\hline \multirow{2}{*}{$P N \_V \_F V \_P P^{F}$} & Arg. Vermiculita & 2,5 & 0,60 & 2,1 & 0,67 & 71,71 \\
\hline & Calda de Cimento & 20,2 & 1,78 & 11,1 & 1,26 & 39,39 \\
\hline \multirow{2}{*}{ PN_V_FV_CC ${ }^{C}$} & Arg. Vermiculita & 3 & 0,40 & 1,8 & 0,69 & 62,32 \\
\hline & Calda de Cimento & 7,4 & 0,84 & 11,8 & 1,33 & 36,02 \\
\hline \multirow{2}{*}{ PN_V_FV_CC } & Arg. Vermiculita & 2 & 0,49 & 1,7 & 0,64 & 92,03 \\
\hline & Calda de Cimento & 28,8 & 3,68 & 14,8 & 1,46 & 28,56 \\
\hline \multirow{2}{*}{ PN_V_A_CC ${ }^{C}$} & Arg. Vermiculita & 2,5 & 0,60 & 2,1 & 0,67 & 71,71 \\
\hline & Calda de Cimento & 20,2 & 1,78 & 11,1 & 1,26 & 39,39 \\
\hline \multirow{2}{*}{ PN_V_A_CC ${ }^{F}$} & Arg. Vermiculita & 2,4 & 0,42 & 1,7 & 0,64 & 74,21 \\
\hline & Calda de Cimento & 22,7 & 1,87 & 11,1 & 1,74 & 40,52 \\
\hline \multirow{2}{*}{ PN_V_SRC } & Arg. Vermiculita & 2,4 & 0,49 & 1,9 & 0,67 & 68,74 \\
\hline & Calda de Cimento & 15,3 & 2,48 & 8,7 & 1,28 & 37,23 \\
\hline \multirow{2}{*}{ PN_V_SRF } & Arg. Vermiculita & 2 & 0,49 & 1,7 & 0,64 & 92,03 \\
\hline & Calda de Cimento & 7,4 & 0,84 & 11,8 & 1,33 & 36,02 \\
\hline
\end{tabular}

C Painéis submetidos ao ensaio de compressão;

F Painéis submetidos ao ensaio de flexão.

TABELA 9: Resistência à compressão dos painéis vazados.

\begin{tabular}{cccc} 
Painel & $\begin{array}{c}P_{\text {teórico }} \\
(\mathrm{kN})\end{array}$ & $\begin{array}{c}\mathrm{P}_{\exp } \\
(\mathrm{kN})\end{array}$ & $\begin{array}{c}\mathrm{P}_{\text {teórico }} \\
P_{\text {exp }}\end{array}$ \\
\hline PN_V_FV_PP & 136,46 & 106,3 & 1,28 \\
PN_V_FV_CC & 97,83 & 47,84 & 2,04 \\
PN_V_A_CC & 449,30 & 241,63 & 1,86 \\
PN_V_SR & 120,85 & 93,13 & 1,30 \\
\hline
\end{tabular}

$$
v_{c}=0,166 \sqrt{f_{c}} b_{w} d
$$

Em que:

$V_{c}=$ resistência ao cisalhamento do concreto;

$\mathrm{f}_{\mathrm{c}}=$ resistência à compressão do concreto;

$\mathrm{b}_{\mathrm{w}}=$ largura da seção transversal;

$d=$ altura de cálculo da seção transversal.

Na Tabela 10 são mostrados os resultados obtidos do ensaio de flexão dos painéis vazados e na Figura 17 o modo de ruína desses painéis. Todos os painéis romperam por força cortante, o que é confirmado pelo fato das menores resistências teóricas terem sido as de cisalhamento. Em nenhum painel foi observado destacamento da calda de cimento do pré-painel de Vermiculita.

Para os painéis reforçados com tela de fibra de vidro e sem reforço, a resistência teórica de cisalhamento avaliada pelo $\mathrm{ACl} 318$ (ACl, 2005) foi mais próxima da resistência experimental, e a favor da segurança. Já para o painel com tela de aço a expressão do Eurocode 2 (CEN, 2004) mostrou-se mais coerente com o resultado experimental. Essa diferença pode ser explicada uma vez que a Equação 1 considera, de forma indireta, o chamado "Efeito de Pino" da armadura longitudinal. Essa contribuição da armadura longitudinal na resistência ao cisalhamento pode 


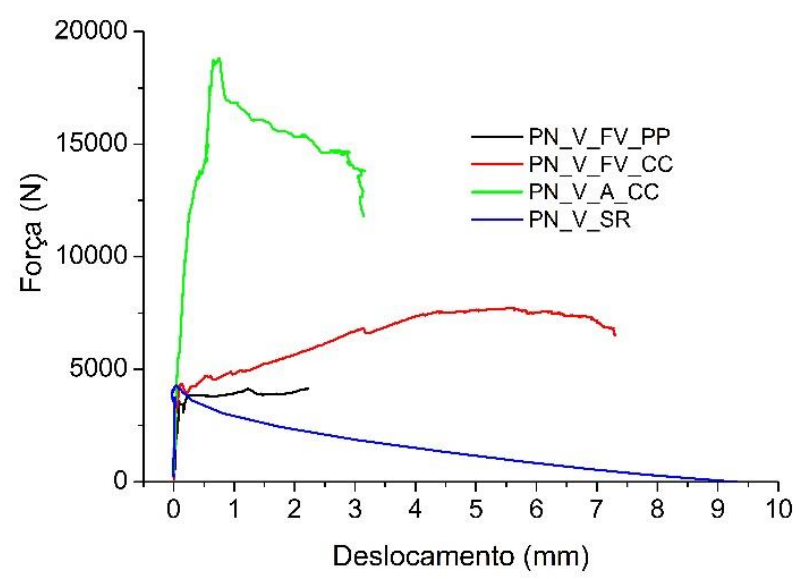

FIGURA 16: Curva força versus deslocamento do ensaio de flexão dos painéis vazados.

\section{TABELA 10: Resistência à flexão dos painéis vazados.}

\begin{tabular}{|c|c|c|c|c|c|c|c|c|}
\hline \multirow{2}{*}{ Painel } & \multirow{2}{*}{$\begin{array}{l}P_{f, t} \\
(k N)\end{array}$} & \multicolumn{2}{|c|}{$P_{s, t}(k N)$} & \multirow{2}{*}{$\begin{array}{c}P_{\text {exp., } 1^{\circ} \text { pico }} \\
(\mathrm{kN})\end{array}$} & \multirow{2}{*}{$\begin{array}{l}P_{\text {exp. }} \\
\text { (kN) }\end{array}$} & \multirow{2}{*}{$\begin{array}{c}\text { Tensão } \\
\text { relativa } \\
(\tau)\end{array}$} & \multirow{2}{*}{\multicolumn{2}{|c|}{$\frac{P_{s, t}}{P_{\exp }}$}} \\
\hline & & Eurocode 2 & $\mathrm{ACl} 318$ & & & & & \\
\hline PN_V_FV_PP & 14,44 & 10,89 & 3,48 & 2,66 & 4,13 & 0,30 & & $0,84^{\prime}$ \\
\hline PN_V_FV_CC & 31,28 & 19,62 & 5,51 & 4,35 & 7,73 & 0,51 & & $0,71^{\prime}$ \\
\hline PN_V_A_CCC & 54,26 & 22,92 & 9,33 & 13,80 & 18,73 & 0,71 & $1,22^{\prime}$ & $0,50^{\prime \prime}$ \\
\hline PN_V̄ & 4,11 & 6,24 & 2,34 & 4,27 & 4,27 & 0,5 & & $0,55^{\prime}$ \\
\hline
\end{tabular}

${ }^{1} P_{s, t}$ é igual à resistência ao cisalhamento segundo o Eurocode 2 (CEN, 2004);

" $\mathrm{Ps}, \mathrm{t}$ é igual à resistência ao cisalhamento segundo $\mathrm{ACl} 318(\mathrm{ACl}, 2005)$.

ser considerada nos painéis com reforço em tela de aço, porém não é significativa quando se utiliza reforço com tela de fibra de vidro.

Para avaliar a eficiência dos painéis e eliminar a influência da variação da resistência e da espessura da calda sobre os resultados obtidos, foi definida uma tensão de cisalhamento relativa $(\tau)$ descrita na Equação 4.

$$
\tau=\frac{P_{\exp }}{b_{w} d \sqrt{f_{c m}}}
$$

Em que:

$\mathrm{P}_{\mathrm{exp}}=$ força última resistida pelo painel e obtida do ensaio;

$\mathrm{f}_{\mathrm{cm}}=$ resistência à compressão do concreto;

$b_{\mathrm{w}}=$ largura das nervuras da seção transversal;

d= altura de cálculo da seção transversal.

O melhor desempenho foi obtido pelo painel com tela de aço (Tabela 10). Os painéis com reforço de fibra de vidro na calda de cimento e sem reforço apresentaram eficiências bastante parecidas. Apesar disso, a presença da tela de fibra de vidro evitou uma ruptura brusca do painel. 0 painel reforçado com tela de fibra de vidro no pré-painel de argamassa com Vermiculita expandida apresentou eficiência inferior ao painel com reforço na calda de cimento. Isso mostra que o melhor posicionamento para a tela de fibra de vidro é na calda de cimento devido à melhor aderência da tela com a calda de cimento.

Os painéis vazados utilizados nos ensaios eram em escala reduzida, enquanto um painel real possui comprimento maior. Apesar disso, a seção transversal utilizada corresponde à seção de um painel real. Utilizando a mesma seção transversal dos painéis ensaiados sem reforço e admitindo um comprimento de $2500 \mathrm{~mm}$, foram feitos simulações para verificar se um painel com calda de cimento de espessura igual a $10 \mathrm{~mm}$ e reforçado com tela de fibra de vidro suportariam carregamentos equivalentes ao de um painel de vedação. 


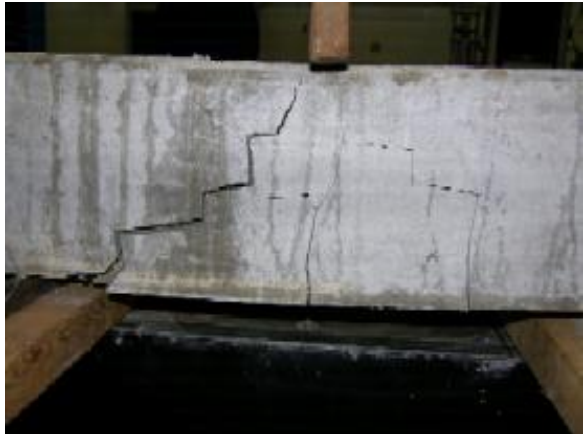

[a]

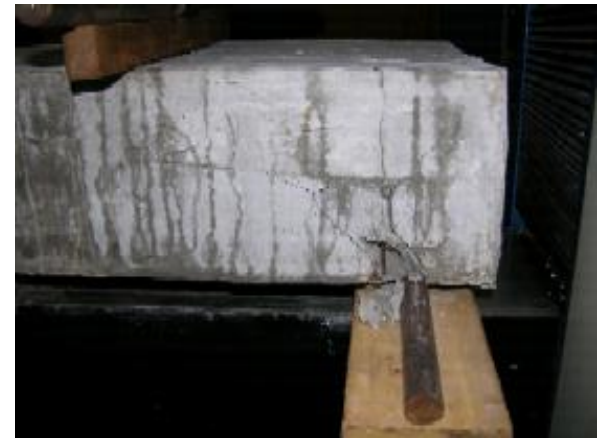

[c]

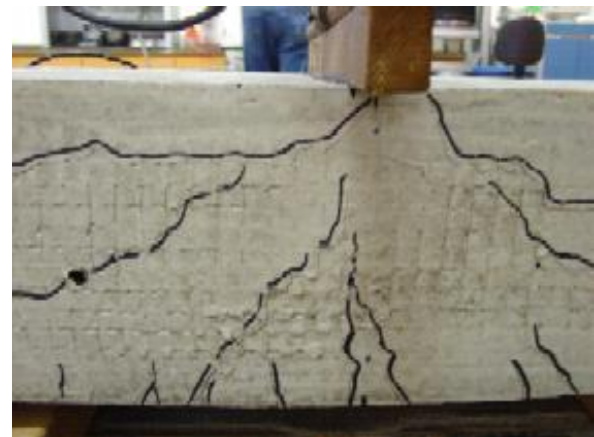

[b]

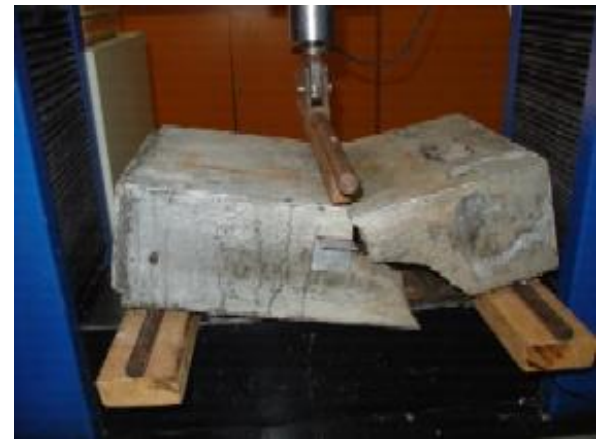

[d]

FIGURA 17: Ruína dos painéis vazados ensaiados à flexão: [a] painel com fibra de vidro no pré-painel (PN_V_FV_PP);

[b] painel com fibra de vidro na calda de cimento (PN_V_FV_CC); [c] painel com tela de aço (PN_V_A_CC); [d] painel sem reforço (PN_V_SR).

A primeira verificação foi para um carregamento distribuído de $1 \mathrm{kN} / \mathrm{m}^{2}$. A segunda verificação foi para uma força concentrada de $2 \mathrm{kN}$ aplicada no meio do vão do painel. Neste caso, primeiro admitiu-se que essa força fosse resistida por apenas um painel de $30 \mathrm{~cm}$ de largura. Em seguida, essa força foi distribuída por três painéis, isto é, admitiu-se que essa força fosse aplicada em um trecho de um metro e que a junta longitudinal entre os painéis fosse resistente o suficiente para garantir o trabalho conjunto dos mesmos.

Para o cálculo do momento fletor resistente foi utilizado o momento de fissuração do painel, isto é, admitiu-se que no Estado Limite Último não seria permitida a fissuração do mesmo. Para o cálculo do esforço cortante resistente foram empregadas as expressões do $\mathrm{ACl} 318(\mathrm{ACl}, 2005)$ transcritas na Equação 2 e na Equação 3. Admitiu- se uma calda de cimento com resistência à compressão característica de $25 \mathrm{MPa}$ e um prépainel com resistência característica à compressão de $3 \mathrm{MPa}$. Os coeficientes de ponderação da solicitação e da resistência do material utilizados são os recomendados no Eurocode 2 (CEN, 2004). A solicitação no painel obtida para os três casos de carregamento bem como os esforços resistentes do mesmo são apresentados na Tabela 11.

Observa-se dessa tabela que um painel com calda de cimento de $10 \mathrm{~mm}$ de espessura é capaz de resistir ao carregamento distribuído e ao carregamento concentrado aplicado em uma faixa de um metro de largura. Caso o carregamento concentrado seja resistido por apenas um único painel, ele resistiria com folga ao esforço cortante, porém não suportaria ao momento fletor sem apresentar fissuras.

TABELA 11: Esforços solicitantes e resistentes em um painel de vedação hipotético.

\begin{tabular}{ccccc} 
Solicitação & \multicolumn{2}{c}{ Esforços solicitantes } & \multicolumn{2}{c}{ Esforços resistentes } \\
\cline { 2 - 5 } & $\mathrm{M}_{\mathrm{d}}(\mathrm{kNm})$ & $\mathrm{V}_{\mathrm{d}}(\mathrm{kN})$ & $\mathrm{Mr}(\mathrm{kNm})$ & $\mathrm{V}_{\mathrm{r}}(\mathrm{kN})$ \\
\hline Carregamento Distribuído & 0,328 & 0,525 & & \\
Carregamento Concentrado (um painel) & 1,750 & 1,400 & 1,581 & 3,048 \\
Carregamento Concentrado (três painéis) & 0,583 & 0,466 & & \\
\hline
\end{tabular}




\section{CONCLUSÕES}

A principal conclusão obtida desse trabalho é a evidência da viabilidade técnica da utilização de painéis vazados leves com pré-painel em argamassa com Vermiculita expandida e reforçados com tela de fibra de vidro. Tal solução pode contribuir para o desenvolvimento de sistemas construtivos em painéis pré-fabricados leves e de melhor isolamento térmico que os tradicionais painéis pré-fabricados em placa cimentícia.

Outras conclusões obtidas da pesquisa são:

(1) A adição de Vermiculita Expandida proporcionou um aumento de cerca de $10 \%$ no isolamento térmico de um painel maciço com $30 \mathrm{~mm}$ de espessura e reforçado com tela de fibra de vidro. Isso pode contribuir para menores variações de temperatura no interior das edificações, gerando redução de gastos com sistemas de refrigeração;

(2) A utilização da tela de fibra de vidro evitou a ruptura brusca nos painéis vazados, que romperam por cisalhamento. 0 posicionamento da tela na calda de cimento dos painéis vazados mostrou-se mais eficiente, pois permitiu um aumento de resistência do painel após o aparecimento da primeira fissura de cisalhamento. Quando a tela estava no pré-painel, o painel foi a ruína logo após o aparecimento da primeira fissura;

(3) Com relação à avaliação teórica da resistência ao cisalhamento em painéis vazados, o Eurocode 2 (CEN, 2004) mostrou-se mais adequado para os painéis com reforço em tela de aço, enquanto o $\mathrm{ACl} 318$ ( $\mathrm{ACl}, 2005)$ apresentou-se mais adequado quando o reforço for em tela de fibra de vidro ou não existir;

A simulação de dimensionamento de um painel vazado com comprimento real indica que o painel ensaiado neste trabalho pode ser aplicado em situações correntes como painel de vedação. Este ainda é um estudo inicial, e novos ensaios em painéis com outras dimensões ainda deverão ser realizados.

\section{AGRADECIMENTOS}

Os autores agradecem o auxílio das empresas Brasil Minérios Ltda., pelo fornecimento da Vermiculita Expandida e Bentonita, Texiglass Indústria e Comércio Ltda, pelo fornecimento da tela de fibra de vidro, e Eletrobrás Furnas pela cessão dos laboratórios onde foram realizados os ensaios. Os autores também são gratos ao apoio financeiro concedido pelo CNPq na forma de bolsa de estudo à aluna. Agradecem, ainda, o apoio do aluno Lucas Motta Oliveira na formatação do texto.

\section{REFERÊNCIAS BIBLIOGRÁFICAS}

AMERICAN CONCRETE INSTITUTE - ACI 213R-87: Guide for Strutural Lightweight Aggregate Concrete. $\mathrm{ACl}$ Manual of Concrete Practice, Part 1. Detroit, Michigan, 1994a.

$\mathrm{ACl}$ 523.3R-93: Guide for Cellular Concretes Above 50pcf, and for Aggregate Concretes above 50pcf with Compressive Strenghts less than 2500psi. $\mathrm{ACl}$ Manual of Concrete Practice, Part 5. Detroit, Michigan, 1994b.

$\mathrm{ACl}$ 318. Building Code Requirements for Structural Concrete (ACl 318-05) and Commentary (ACI 318R-05). ACl Manual of Concrete Practice. Detroit, Michigan, 2005

AMERICAN SOCIETY FOR TESTING AND MATERIALS ASTM C 332. Standard Specification for Lightweight Aggregates for Insulating Concrete. United States, 2000.

ASSOCIAÇÃO BRASILEIRA DE NORMAS TÉCNICAS - ABNT. NBR-EB 230. Agregados Leves para Concreto Estrutural. Rio de Janeiro, RJ, 1969.

NBR-6207. Arame de aço - Ensaio de tração. Rio de Janeiro, 1982.

NBR-7213. Agregados Leves para Concreto Isolante Térmico. Rio de Janeiro, RJ, 1984.

NBR-9778. Argamassa e concreto endurecidos - Determinação da absorção de água por imersão Índice de vazios e massa específica. Rio de Janeiro, 1987.

NBR-12820/93: Concreto Endurecido Determinação da condutividade térmica. Rio de Janeiro, 1993.

NBR-5739. Concreto - Ensaios de compressão de corpos-de-prova cilíndricos. Rio de Janeiro, 1994a. 
NBR-7222. Argamassa e concreto -

Determinação da resistência à tração por compressão diametral de corpos-de-prova cilíndricos. Rio de Janeiro, 1994b.

NBR-8522. Concreto - Determinação dos módulos estáticos de elasticidade e de deformação e da curva tensão-deformação. Rio de Janeiro, 2003.

COMITÉ EUROPÉEN DE NORMALISATION - CEN. EUROCODE 2: Design of concrete structures - Part 1.1: General rules and rules for buildings. Brussels, Belgium, 225 p., 2004

EL DEBS, M. K.; EL DEBS, A. L. H. C.. Bending behaviour of thin walled elements of Portland cement mortar reinforced with fiber glass wires. In: 8th International Symposium on Fiber Reinforced Polymer Reinforcement for Concrete Structures, 2007, Patras. INTERNATIONAL SYMPOSIUM ON FIBER-REINFORCED POLYMER REINFORCEMENT FOR CONCRETE STRUCTURES, 8, 2007. 1-8 $\mathrm{p}$.

MACHADO JUNIOR, E. F. ; EL DEBS, M. K. ; HANAI, J. B. ; TAKEYA, T. . Ferrocement sandwich walls. Journal of Ferrocement, Vol. 30, n. 1, 2000, 45-58 p.

$\mathrm{MU}$, B.; MEYER, C. Flexural behavior of Fiber MeshReinforced Concrete with Glass Aggregate. ACl Materials Journal, Vol. 99, n. 5, 2002.

PINTO, C. A. O. M.; KOZIEVITCH, V. F. J.; HAMASSAKI, L.; VIEIRA COELHO, A. C.; XAVIER, C.; BÜNCHLER, P. M.; VALENZUELA DIAZ, F. R. Influência das Argilas nas Propriedades de Pastas de Cimento Portland. Parte 2: Sistema contendo Bentonita Sódica e Vermiculita e Sistema contendo Bentonita Sódica e Argila Organofílica. In: Congresso Brasileiro de Engenharia e Ciência dos Materiais, 14, São Pedro, São Paulo, 2000.

SHAO, Y.; BLAIN-COSGROVE, E.; ROBINSON, B. Structural Evaluation of Cement Skin Sandwich Building System. In: Dubey, A. (Org.). Thin Reinforced Cement-based Products and Construction Systems - SP 224. Farmington Hills: American Concrete Institute, 2004, 101-111 p.

TENÓRIO, H. O.; ARAÚJO, D. L.; CAMPOS, H. S. V.; BITTENCOURT, R. M. Traços de Concreto para Painéis Pré-Moldados Contendo Vermiculita Expandida: Propriedades Mecânicas. In: Congresso Nacional do Concreto, 47, 2005, Olinda. Anais...São Paulo: Ibracon, 2005a, Vol. XI, 387-397 p.

TENÓRIO, H. O.; ARAÚJO, D. L.; CAMPOS, H. S. V.; BITTENCOURT, R. M. Traços de Argamassa para Painéis Pré-Moldados Contendo Vermiculita Expandida: Propriedades Mecânicas e Térmicas. In: Congresso Nacional do Concreto, 47, 2005, Olinda. Anais...São Paulo: Ibracon, 2005b, Vol. XI, 371-386 p.
TENÓRIO, H. O. Painel Sanduíche com Núcleo em Vermiculita Expandida: Análise da Eficiência do Conector Tipo Treliça na Rigidez do Painel. 2005. $229 f$. Dissertação (Mestrado em Engenharia Civil) - Escola de Engenharia Civil, UFG-GO, 2005. 